\title{
ЭПИДЕМИОЛОГИЯ ЭНДОКРИННОЙ ПАТОЛОГИИ У ДЕТЕЙ ЯРОСЛАВСКОЙ ОБЛАСТИ
}

\author{
В.В. Туз, Е.В. Щедрова, Н.А. Ломоносова, О.В. Макина, О.В. Кисельникова \\ ГБУз ЯО Областная детская клиническая больнича, \\ ФГБОУ ВО Ярославский государственный медицинский университет
}

ВВЕДЕНИЕ: Эпидемиология эндокринных заболеваний отличается не только в различных странах, но и в различных регионах России.

Цель исследование: исследовать распространенность основных эндокринных заболеваний в Ярославской области.

РЕЗУЛЬТАТЫ: Патология эндокринной системы у детей в Ярославской области за последние десятилетия имеет неуклонную тенденцию к росту. Численность детского населения до 18 лет на 2020 г. составляет 264 тыс. человек, из них 82,4\% городских детей. Среди эндокринной патологии превалируют такие нозологические единицы, как ожирение, сахарный диабет 1 типа (СД1) и патология щитовидной железы. Количественная характеристика заболеваний эндокринной системы представлена в таблице 1.

Табл. 1. Количественная характеристика эндокринной патологии у детей по Ярославской области за 2020 год

\begin{tabular}{lcc}
\hline \multicolumn{1}{c}{ Нозология } & Bсего & $\begin{array}{c}\text { В т.ч. впервые } \\
\text { выявленный в 2020 г. }\end{array}$ \\
\hline Сахарный диабет 1 типа & 537 & 97 \\
Сахарный диабет 2 типа & 10 & 2 \\
Врождённый гипотиреоз & 32 & 1 \\
Диффузный токсический зоб & 14 & 2 \\
Узловой зоб & 112 & 26 \\
Тиреоидиты & 301 & 77 \\
Рак щитовидной железы & 5 & 1 \\
Врождённая дисфункция коры надпочечников & 24 & 1 \\
Ожирение & 1673 & 303 \\
Гипофизарный нанизм & 43 & 5 \\
Синдром Шерешевского-Тернера & 8 & 1 \\
Преждевременное половое развитие & 21 & 5 \\
Нарушение формирования пола & 4 & 0 \\
Гипопаратиреоз & 4 & 1 \\
Врождённый гиперинсулинизм & 3 & 0 \\
\hline
\end{tabular}

Ярославская область занимает лидирующее место по распространённости СД1 среди детей и подростков по Центральному Федеральному Округу на протяжении последних лет. На конец 2020 г. на учёте состоит 537 детец с СД, из них 8 человек с СД 2 типа. Распространенность СД1 составила 222 на 100 тыс. дет. нас., заболеваемость СД1 40 на 100 тыс. дет. нас. За последний год отмечен резкий подъём показателей, не исключена связь с COVID-19. Заболеваемость детей СД 


\section{СБОРНИК ТЕЗИСОВ}

XVII Российская научно-практическая конференция детских эндокринологов «Достижения науки в практику детского эндокринолога»

1 типа в Ярославской области неуклонно возрастает и по сравнению со среднеевропейскими показателями (16,3 на 100 тыс. детей) превосходит 2,5 раза. Увеличивается количество детей, заболевших СД1 в дошкольном возрасте. Заболеваемость среди детей данного возраста сохраняется на высоком уровне и достигает периодически $50 \%$.

Следствием поздней диагностики является состояние детей при поступлении в стационар. 51\% детей поступает в среднетяжелом состоянии без признаков кетоза и 49\% - с кетоацидозом, требующие проведения интенсивной терапии, из них 34\% в крайне тяжелом состоянии, нуждающиеся в реанимационной помощи. В дальнейшем это приводит к более ранним появлениям хронических осложнений и назначением более высоких доз инсулина, а также представляет непосредственную угрозу для жизни ребенка.

Таким образом, несвоевременная диагностика СД 1 типа и поздняя госпитализация больных в состоянии клинико-метаболической декомпенсации может быть связана с быстрым развитием критического состояния у детей после появления первых признаков заболевания, с недостаточным вниманием к состоянию ребенка в семье, даже при наличии отягощенной наследственности по СД; с недооценкой симптомов заболевания со стороны врачей первичного звена, а также специалистов, к которым первоначально попадают дети вследствие полиморфизма клинической картины дебюта СД.

По нашим представлениям, эта информация должна быть хорошо известна, в первую очередь, врачам педиатрам первичного звена детского здравоохранения, так как именно они впервые сталкиваются с дебютом СД у детей, и именно они определяют дальнейшую тактику ведения таких больных. Необходимо создать настороженность педиатров всех специальностей в отношении СД 1 типа не только тогда, когда клиническая картина явная, но и тогда, когда ее вообще нет, а у ребенка имеются предрасполагающие факторы или имеется какой-либо нетипичный синдром.

Второе место по обращаемости среди эндокринной патологии занимает проблема избыточного веса у детей и подростков. С каждым годом увеличивается количество детей с избыточной массой тела и ожирением. Вероятно, это связано с малой физической активностью детей, нерациональным и гиперкалорийным питанием. Большинство пациентов находится под наблюдением эндокринологов поликлиник, в отделение поступают дети с осложненными формами ожирения для выявления нарушений всех видов обмена, сопутствующей патологии и обучения принципам правильного питания, подбора комплекса физических упражнений. Все чаще выявляется ожирение, осложненное нарушениями углеводного обмена, такими как нарушение толерантности к глюкозе, гиперинсулинемией и инсулинорезистентностью, из нарушений липидного обмена гиперхолестеринемией и дислипидемией, участились случаи выявления жировой инфильтрации печени. У подростков, как правило, ожирение осложнено гипоталамическим синдромом и артериальной гипертензией. Стоит отметить формирование хронической болезни почек у детей с осложнённым ожирением (метаболическим синдромом), к которой приводят абдоминальное ожирение и инсулинорезистентность, активируя склерозирование клубочков и повышение внутриклубочкового давления.

Для расширения обслуживания пациентов с ожирением в амбулаторной сети функционируют дневные стационары, где дети с данной проблемой обследуются, получают лечение, занимаются в специализированных группах ЛФК. Планируется открытие Школы здоровья по борьбе с избыточным весом у детей и подростков.

Заболевания щитовидной железы занимают 3 место по частоте обращаемости эндокринной патологии. В основном диагностируются такие изменения со стороны щитовидной железы, как множественные коллоидные образования, аутоиммунный тиреоидит, диффузный нетоксический 3об, узловой или многоузловой зоб, субклинический гипотиреоз, реже диффузный токсический 306 и злокачественные новообразования. За последние годы увеличилось количество детей с аутоиммунным тиреоидитом и коллоидно-узловыми зобами.

В последние годы обращает внимание тенденция к увеличению выявления среди нарушений роста гипофизарного нанизма - 43 человека. Распространённость составила 16,2 детей 
на 100 тыс. дет. нас., что превышает среднее значение по РФ (12,3/100 тыс.дет.нас.). Стимуляционная проба с инсулином позволяет подтвердить генез СТГ-дефицита. Все дети получают заместительную терапию соматотропным гормоном по программе «7 нозологий».

Нарушение полового развития в нашем регионе преимущественно занимает преждевременное половое развитие (ППР). Распространённость ППР по Ярославской области на 2020 г. составила 7,95 случаев на 100000 детского населения, что несколько выше по РФ в целом (5/100 тыс.дет.нас.). Проводимая стимуляционная проба с гонадотропин-рилизинг-гормоном (диферелин) позволяет дифференцировать гонадотропинзависимые формы ППР от гонадотропин-независимых и от изолированного телархе у девочек.

Таким образом, патология эндокринной системы у детей в Ярославской области довольна разнообразна, превышает частоту распространения по сравнению со средними значениями по России. Лабораторно-диагностическая служба позволяет выявлять эндокринную патологию у детей с раннего возраста. В городе функционируют две Школы Здоровья по проблемам сахарного диабета у детей и подростков. Хотелось бы расширить обследование генетического профиля, а также увеличить количество штатных ставок детских эндокринологов как в городе, так и в областных регионах. 